\title{
PYROLYSIS MASS SPECTROMETRIC ANALYSIS OF STYRENE-BUTADIENE BLOCK AND RANDOM COPOLYMERS
}

\author{
JALE HACALOGLU,*1 TANER ERSEN, ${ }^{1}$ NERGIS ERTUGRUL, ${ }^{\prime}$ \\ MUHAMMED M. FARES ${ }^{1}$ and SEFIK SUZER ${ }^{2}$ \\ 'Middle East Technical University, Chemistry Department, 06531 Ankara, Turkey \\ ${ }^{2}$ Bilkent University, Chemistry Department, 06533 Ankara, Turkey
}

(Received 3 June 1995; accepted in final form 25 October 1995)

\begin{abstract}
Direct pyrolysis mass spectrometric analysis of a styrene-butadiene-styrene block copolymer indicated that thermal decomposition of each block shows a resemblance to the related homopolymer, giving a possibility of differentiation of blocks. However, the random analog, the styrene butadiene rubber, degraded in a manner that is somewhat in between in nature of the thermal characteristics of both homopolymers. This technique shows promise to differentiate thermal behaviors of each sequence in block polymers if any exist. Indirect pyrolysis mass spectrometric analysis gave no clear evidence for differentiation of the nature and the composition of the copolymers. (C) 1997 Elsevier Science Ltd. All rights reserved
\end{abstract}

\section{INTRODUCTION}

Thermal decomposition of polystyrene and polybutadiene have received considerable attention [1-15]. It is established that in vacuum and oxygen free atmosphere thermal degradation of polystyrene (PS) at elevated temperatures (below $300^{\circ} \mathrm{C}$ ) is initiated by random scissions of the main chain without evolution of the low molecular weight volatile products to give primary and secondary macroradicals which depolymerize by unzipping reactions and mainly produce the monomer [1-7]. Furthermore, the effect of polymerization technique, initiator used, and irregularities on thermal behavior are also well established $[8,9]$. Considerable work on thermal decomposition of polybutadiene (PB) has also appeared in the literature [10-15]. It is proposed that thermal degradation of PB occurs readily at the sites $b$ to the double bonds, as the presence of a double bond introduces a weakness in bonds which are $b$ position to it. The free radicals produced unzip to yield the monomer. Bond scissions may also be accompanied by $\mathrm{H}$-transfers resulting in the formation of saturated and unsaturated ends. Thermal degradation of BP samples having different initial contents of cis-1-4, trans-1-4 and 1,2 units were also investigated. However, only limited information is available on thermal behavior of butadiene-styrene copolymers $[4,16]$.

Recently, we applied direct and indirect pyrolysis mass spectrometric techniques in thermal analysis of styrene-isoprene-styrene copolymer [17]. Now, we report the results of direct and indirect pyrolysis mass spectrometric analysis of styrene-butadiene-styrene

*To whom all correspondence should be addressed.
(SBS) (block copolymer) and styrene-butadiene rubber (random copolymer).

\section{EXPERIMENTAL}

Direct and indirect pyrolysis mass spectrometric systems were described previously $[7,17,18]$. Direct pyrolysis MS equipment consists of a direct insertion probe, a stainless steel tube Ag-soldered to a copper sample holder assembly, its control unit, a Balzers QMG 311 quadruple mass spectrometer and a personal computer for control of the instrument, data acquisition and processing. In the case of indirect pyrolysis (evolved gas analysis) by MS the same system with a pyrolysis chamber instead of the probe is used. The pyrolysis chamber is made from a Pyrex reactor and an oven is used for heating.

Styrene-butadiene-styrene, SBS (Kraton D 1101, styrene:butadiene ratio 31:69), and styrene-butadiene rubber, SBR (SBR-1502, styrene:butadiene ratio 25:75), were obtained from Shell Co. (Istanbul), cis-polybutadiene, PB, was obtained from PETKIM (Turkish Petrochemical Industries) and polystyrene, PS, was supplied by Aldrich. For direct pyrolysis experiments samples cast in the form of thin films from $20 \mathrm{~mL} 0.1 \% \mathrm{~m} / \mathrm{v}$ polymer-benzene solutions on to copper sample holders were subjected to thermal degradation under high vacuum $\left(10^{-7} \mathrm{mbar}\right)$ by increasing the temperature rapidly to $100^{\circ} \mathrm{C}$ and then by heating at a rate of $5^{\circ} \mathrm{C} / \mathrm{min}$. For indirect pyrolysis experiments, $1.0 \mathrm{mg}$ fine powder samples were heated at a rate of typically $10^{\circ} \mathrm{C} / \mathrm{min}$. Duplicate experiments indicated that pyrolysis products and temperature ranges of decomposition were reproducible.

\section{RESULTS AND DISCUSSION}

\section{Direct pyrolysis}

Thermal decomposition of styrene-butadienestyrene copolymer, SBS, and styrene-butadiene rubber, $S B R$, were studied by recording mass spectra as a function of temperature. The temperature values 
corresponding to maximum thermal degradation yields from both samples were quite similar at $213^{\circ} \mathrm{C}$ and $217^{\circ} \mathrm{C}$ for SBS and SBR, respectively. Furthermore, similar peaks were detected in the pyrolysis mass spectra of both polymers. The more intense and/or characteristic peaks observed in the spectra are collected in Table 1 with assigned chemical formulae. The summary of pyrolysis mass spectra of related homopolymers, polystyrene (PS) and polybutadiene (PB) at temperatures corresponding to their maximum decomposition yields $\left(230^{\circ} \mathrm{C}\right.$ for PS and $225^{\circ} \mathrm{C}$ for $\mathrm{PB}$ ) are also included for comparison.

Note that mass spectra of the copolymers can be classified into two main groups:

(a) Ions mainly due to butadiene block such as $\mathrm{C}_{4} \mathrm{H}_{6}^{+}$at $54 \mathrm{amu}$ (butadiene monomer), $\mathrm{C}_{5} \mathrm{H}_{7}^{+}$ at $67 \mathrm{amu}, \mathrm{C}_{6} \mathrm{H}_{7}^{+}$at $81 \mathrm{amu}, \mathrm{C}_{8} \mathrm{H}_{12}^{+}$at $108 \mathrm{amu}$ (butadiene dimer), $\mathrm{C}_{12} \mathrm{H}_{18}^{+}$at $162 \mathrm{amu}$ (butadiene trimer), $\mathrm{C}_{16} \mathrm{H}_{24}^{+}$at 216 amu (butadiene tetramer) and $\mathrm{C}_{20} \mathrm{H}_{30}^{+}$at $270 \mathrm{amu}$ (butadiene pentamer).

(b) Ions mainly due to styrene block such as $\mathrm{C}_{5} \mathrm{H}_{5}^{+}$ at $65 \mathrm{amu}, \mathrm{C}_{6} \mathrm{H}_{5}^{+}$at $77 \mathrm{amu}, \mathrm{C}_{7} \mathrm{H}_{7}^{+}$at $91 \mathrm{amu}, \mathrm{C}_{8} \mathrm{H}_{8}^{+}$ at $104 \mathrm{amu}$ (styrene monomer) and $\mathrm{C}_{16} \mathrm{H}_{16}^{+}$at $208 \mathrm{amu}$ (styrene dimer). These ions were also detected, in very small yields, during the pyrolysis of PB. However, they are not regarded as diagnostic for $\mathrm{PB}$.
(Table 1), it can be concluded that degradation proceeded by random bond scissions at points I, II and III.

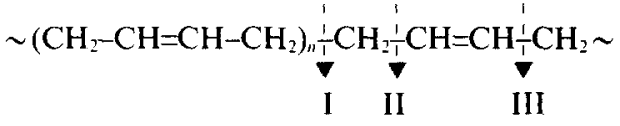

Groups of ions produced due to cleavages at position I were in general more abundant. It is known that cleavage occurs more readily at the sites $\beta$ to the double bonds, as the presence of double bonds weakens the adjacent $\mathrm{C}-\mathrm{C}$ bonds. In spite of this general trend the 67 amu peak was the base peak from SBS and PB and the peak at 81 amu was among the most abundant. It may be assumed that cyclopentene and cyclohexene were produced during thermal decomposition due to cleavages at a $\alpha$ positions followed by cyclization reactions. The ions at 67 and $81 \mathrm{amu}$ may be generated from these molecules during electron impact ionization in the ion source of the mass spectrometer by $\mathrm{H}$ losses. Thus it may be concluded that degradation of butadiene block proceeds mainly through $\alpha$ and $\beta$ chain scissions, yielding fragments that can be stabilized by cyclization reactions:

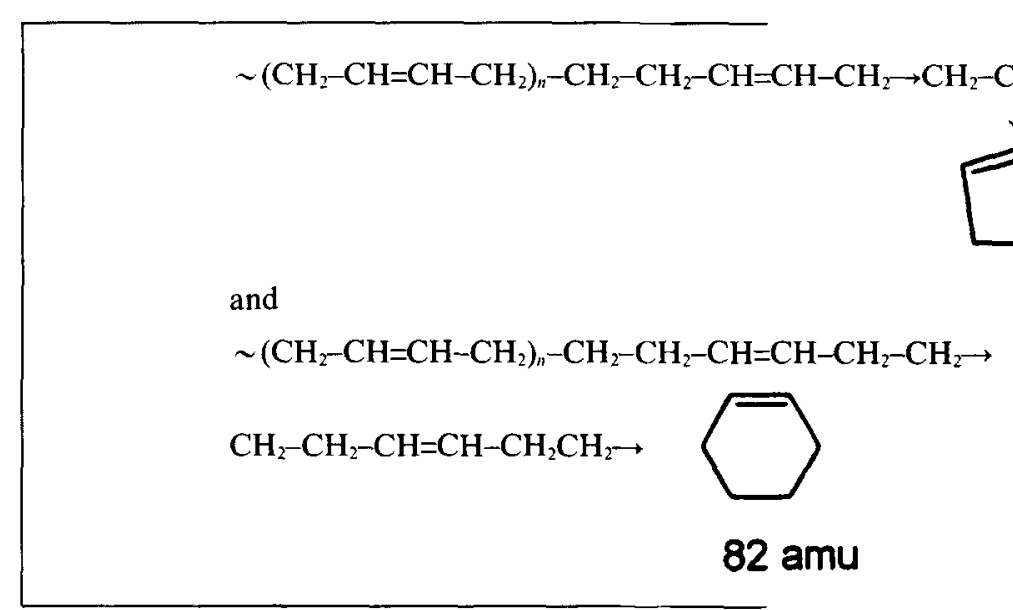

The relative intensities of peaks observed from SBS were noticeably similar to those observed from PB. However, there existed considerable differences in the relative intensities of peaks observed from SBS and SBR. The base peak was at 67 amu $\left(\mathrm{C}_{6} \mathrm{H}_{7}^{+}\right)$in the pyrolysis mass spectra of SBS and at 91 amu $\left(\mathrm{C}_{7} \mathrm{H}_{7}^{+}\right)$ in the case of SBR. Furthermore, the relative intensities of all the peaks, arising mainly from butadiene sequence, were more pronounced when they were produced during the thermal decomposition of SBS. This trend may be directly related to styrene/butadiene ratios in these samples being 25/75 in SBR and 31/59 in SBS. Yet in both spectra, the relative intensity of the peak at $108 \mathrm{amu}$ due to 4-vinylcyclohexene, the butadiene dimer, was quite similar. This indicates that the decomposition paths in the block and random samples are certainly different.

Considering the products related to butadiene sequences in all three polymers, SBS, SBR and PB
The relative intensities of styrene sequence related peaks from the copolymers were somewhat different from the PS homopolymer. The peak at 104 amu due to the styrene monomer was the most intense from polystyrene, indicating that degradation was initiated by random scissions of the main chain to yield primary and secondary macroradicals which depolymerize to the monomer in accordance with the literature findings [1-7]. Yet, in the case of the copolymer, the peak at 91 amu, most probably due to troplyium ion, was more abundant. Nevertheless, one should take into account the production of the same peak from the butadiene units (see the pyrolysis mass data of PB in Table 1). Thus, a similar degradation mechanism for the styrene blocks in the copolymer can be assigned as in the case of the homopolymer.

Another point that should be pointed out is that the present results indicated a lower stability for PB compared to PS. This behavior was contrary to previous relative stability results. The $T_{\mathrm{h}}$ value (the 
Table 1. Relative intensities and assigned chemical formulae of some characteristic and/or intense peaks observed during the direct pyrolysis of SBS at 213 and $231 \mathrm{C}$, SBR at $219 \mathrm{C}$. PB at $225 \mathrm{C}$

\begin{tabular}{lrrrrrl}
\multicolumn{7}{c}{ and PS at 230 C } \\
\hline $\mathrm{m} / \mathrm{z}$ & SBS & SBS & SBR & PB & PS & \\
$T(\mathrm{C})$ & 213 & 231 & 219 & 225 & 230 & \multicolumn{1}{c}{ Assignment } \\
\hline 54 & 450 & 119 & 257 & 556 & 7 & Butadiene monomer ion \\
67 & 1000 & 374 & 583 & 1000 & 31 & $\mathrm{C}_{5} \mathbf{H}_{7}^{+}$ \\
77 & 300 & 463 & 396 & 298 & 369 & $\mathrm{C}_{6} \mathbf{H}_{5}^{+}$ \\
81 & 808 & 415 & 585 & 700 & 5 & $\mathrm{C}_{6} \mathbf{H}_{9}^{+}$ \\
82 & 337 & 203 & 289 & 366 & 3 & $\mathrm{C}_{6} \mathbf{H}_{10}^{+}$ \\
91 & 583 & 1000 & 1000 & 530 & 967 & $\mathrm{C}_{7} \mathbf{H}_{7}^{+}$tropylium ion \\
95 & 343 & 263 & 341 & 398 & 5 & $\mathrm{C}_{7} \mathbf{H}_{11}^{+}$ \\
96 & 194 & 157 & 155 & 182 & 3 & $\mathrm{C}_{7} \mathbf{H}_{12}^{+}$ \\
104 & 196 & 753 & 507 & 135 & 1000 & Styrene monomer ion \\
108 & 236 & 125 & 223 & 282 & 1 & Butadiene dimer ion \\
121 & 221 & 117 & 234 & 285 & 1 & $\mathrm{C}_{9} \mathbf{H}_{13}^{+}$ \\
136 & 122 & 98 & 110 & 147 & - & $\mathrm{C}_{10} \mathrm{H}_{16}^{+}$ \\
162 & 103 & 122 & 84 & 121 & - & Butadiene trimer ion \\
208 & 99 & 65 & 60 & 20 & 25 & Styrene dimer ion \\
216 & 12 & 8 & 24 & 37 & - & Butadiene tetramer ion \\
270 & 4 & 3 & 10 & 14 & - & Butadiene pentamer ion \\
\hline
\end{tabular}

temperature corresponding to $50 \%$ loss of weight of the polymer) of polybutadiene is considerably higher than that of polystyrene [19] $\left(407^{\circ} \mathrm{C}\right.$ for $\mathrm{PB}$ and $364^{\circ} \mathrm{C}$ for PS). Thermogravimetric (TG) and differential thermogravimetric (DTG) studies [12] showed that decomposition of polybutadiene under nitrogen atmosphere occurs in two stages. Decomposition temperatures fall in the range $370-385^{\circ} \mathrm{C}$ for the first stage and between $460-475^{\circ} \mathrm{C}$ for the second one. Differential scanning calorimetric (DSC) results indicated that the first decomposition was an exothermic process, probably due to extensive cyclization reactions. The wcight loss in the first degradation step was less than $15 \%$. However, in our dynamic high vacuum conditions weight loss should be more pronounced, even at low temperatures.

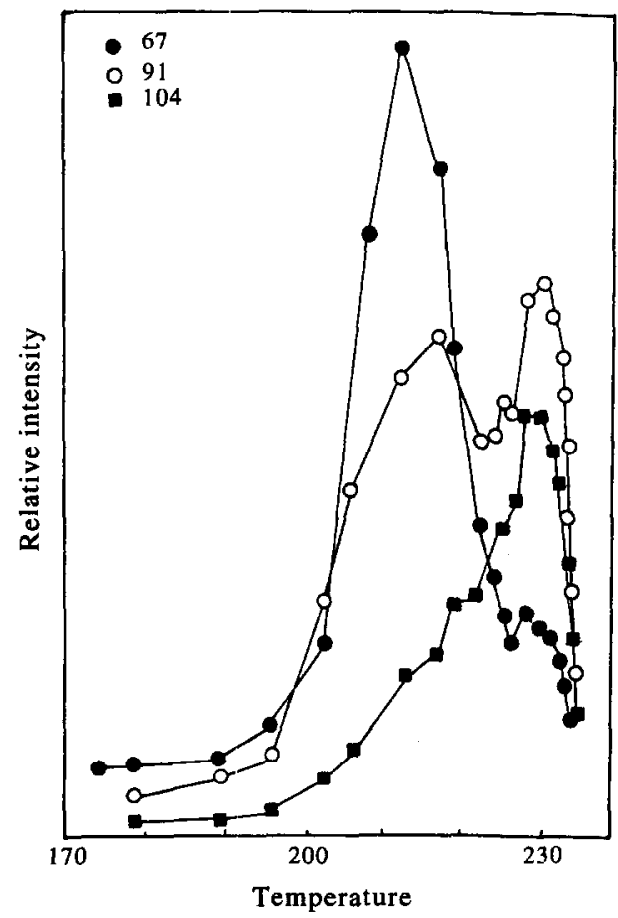

Fig. 1. Ion-temperature profiles of some characteristic fragments observed during the direct pyrolysis of SBS.
In order to get a better insight, the ion-temperature plots, variation of intensities as a function of temperature, were studied. In Figs 1 and 2 the ion-temperature plots of peaks at $67 \mathrm{amu} \mathrm{C}_{5} \mathrm{H}_{7}^{+}$, $77 \mathrm{amu} \mathrm{C}_{6} \mathrm{H}_{5}^{+}, 91 \mathrm{amu} \mathrm{C}_{7} \mathrm{H}_{7}^{+}, 104 \mathrm{amu} \mathrm{C}_{8} \mathrm{H}_{8}^{+}$and $108 \mathrm{amu} \mathrm{C}_{8} \mathrm{H}_{12}^{+}$observed from SBS and SBR are given. Notice that two maxima exist in the ion-temperatures plots of SBS at $213^{\circ} \mathrm{C}$ and $231^{\circ} \mathrm{C}$ indicating a two stage decomposition, while only a single maximum at $217^{\circ} \mathrm{C}$ is present in ion-temperature plots in the case of SBR. It is clear that the peaks stemming mainly from the butadiene block gave a maximum at $213^{\circ} \mathrm{C}$, whercas the peaks that were mainly related to the styrene block showed a maximum at $231^{\circ} \mathrm{C}$. The normalized mass spectrum at $231^{\circ} \mathrm{C}$ is also included in Table 1 . To our surprise

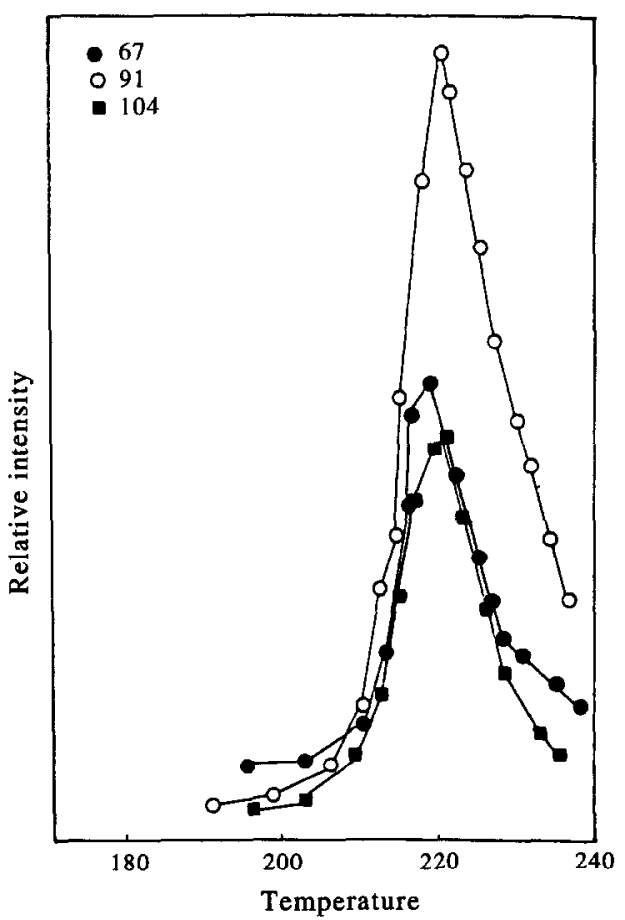

Fig. 2. Ion-temperature profiles of some characteristic fragments observed during the direct pyrolysis of SBR. 


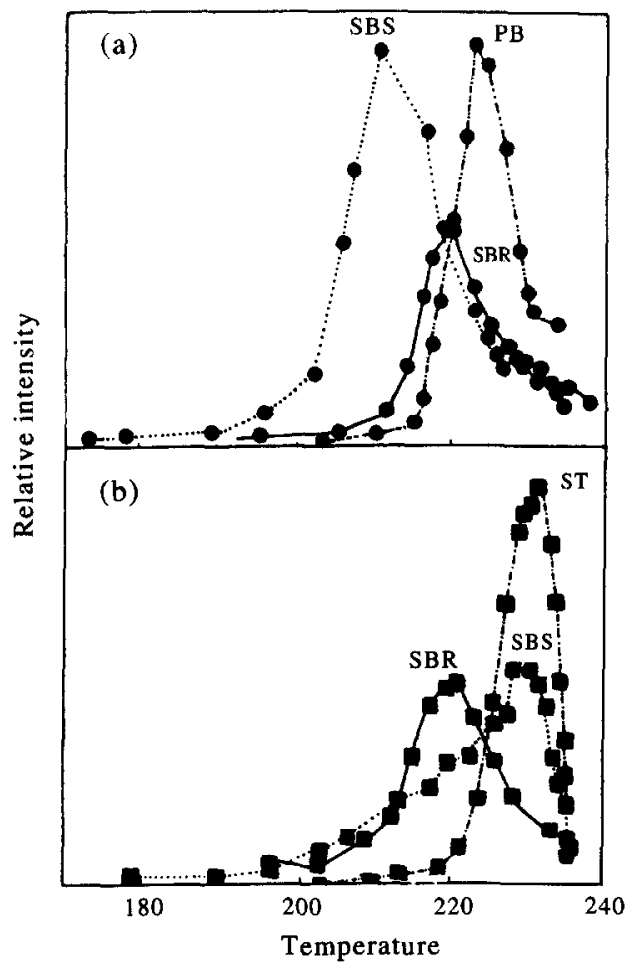

Fig. 3. Ion-temperature profiles of (a) $\mathrm{C}_{5} \mathrm{H}_{7}^{+}$at $67 \mathrm{amu}$ observed during the direct pyrolysis of SBS, SBR and PB, and (b) $\mathrm{C}_{8} \mathrm{H}_{8}^{+}$at $104 \mathrm{amu}$ (styrene) observed during the direct pyrolysis of SBS, SBR and PS.

this spectrum was much more identical to the pyrolysis mass spectrum of SBR at $217^{\circ} \mathrm{C}$ with the base peak at $91 \mathrm{amu}\left(\mathrm{C}_{7} \mathrm{H}_{7}^{+}\right)$.

To make a better comparison between the copolymers under investigation and the related homopolymers, variations of intensities of peaks at 67 and $104 \mathrm{amu}$ as a function of temperature during the thermal decomposition of SBS, SBR and PB and SBS, SBR and PS are plotted in Fig. 3 [(a) and (b), respectively]. As can be seen from Fig. 3, the peak started to appear in the pyrolysis mass spectra of SBS around $190^{\circ} \mathrm{C}$. The temperatures at which degradation started in SBR and PB shifted to 210 and $215^{\circ} \mathrm{C}$, respectively. Another point that can be noticed directly from the figure is that the decomposition temperature range gets narrower in the order SBS > SBR > PB [Fig. 3(a)]. The temperature at which maximum degradation yield was observed also shifted to higher values in the same order: 213,219 and $225^{\circ} \mathrm{C}$ for SBS, SBR and PB, respectively. Note that the SBR decomposition range overlaps with that of SBS and the high temperature range of both of the copolymers overlaps with that of PB. The decomposition range yielding styrene is also narrower in polystyrene compared to those observed in the copolymers [Fig. 3(b)]. Furthermore, the temperature range in which styrene production was detected from SBS covers those of both SBR and PS. The maximum decomposition yield of $104 \mathrm{amu}$ fragment produced from SBS at $231^{\circ} \mathrm{C}$ is very close to that observed from polystyrene (at $230^{\circ} \mathrm{C}$ ). A shoulder around $219^{\circ} \mathrm{C}$ is also present in the ion-temperature profile of fragment $104 \mathrm{amu}$ from
SBS. This temperature is the temperature at which maximum styrene production occurs from SBR.

These observations lead us to conclude that thermal stability and behavior of each block in the block copolymer resembles the corresponding homopolymer more than the random copolymer. Yet, each unit also influences every other to some extent in the block copolymer. In general, thermal stability is lower in these copolymers. However, this may also be directly related to the molecular weight of each repeating unit. It is known that an increase in molecular weight increases thermal stability. Therefore, it is not possible to make strict conclusions on the influence of each unit on the thermal stability of the other. Actually, the effect should be more pronounced in the random copolymer. Each block can be expected to behave independently in the block copolymer when the chain lengths are sufficiently long. The experimental observations are in accordance with this fact. The ion-temperature profiles of fragments from SBS showed two maxima, indicating that each unit in the copolymer decomposed independently, whereas the single maximum in the ion-temperature profiles of SBR pointed out that each unit affected every other considerably. Shoulders at high temperature ranges may be related to the presence of relatively long chain units along the random copolymer.

\section{Indirect pyrolysis}

Indirect pyrolysis analysis of both copolymers did not indicate any sign that can be used to differentiate block and random copolymers from each other. The peaks that may be related to styrene units, such as those at 51, 78, 91 and $104 \mathrm{amu}$, were more intense. This is an unexpected trend considering the compositions and the direct pyrolysis results of the copolymers. It is most likely that the products observed during the indirect pyrolysis mass spectrometric analysis are not the primary decomposition products but mainly secondary reaction products produced in the pyrolysis chamber. A similar behavior was observed in the pyrolysis mass spectrometric analysis of styrene-isoprene-styrene block copolymer [17].

\section{CONCLUSION}

The present work points out that direct pyrolysis MS technique can be used to differentiate block and random copolymers from each other. It is found that each block in a SBS copolymer behaved independently during thermal decomposition following the same degradation pathways of the related homopolymers. Similar products were also observed for the random copolymer, SBR. Yet, it was not possible to differentiate different blocks in this sample. Indirect pyrolysis analysis showed no clear evidence for determining the nature (random or block) and composition of the copolymers under investigation.

\section{REFERENCES}

1. Ohtani, H., Yuyama, T., Tsuge, S., Plage, P. and Schulten, H. R., Eur. Polym. J., 1990, 26, 93. 
2. Luderwald, I. and Vogl, O., Macromol. Chem., 1972, 180, 2302.

3. Guaita, M., Brit. Polym. J., 1986, 18, 226.

4. Erdogan, M., Yalcin, T., Tincer, T. and Suzer, S., Eur Polym. J., 1991, 27, 413.

5. Shapi, M. M. and Hesso, A., J. Anal. Appl. Pyrolyis, $1990,18,143$.

6. Ohtani, H., Ueda, S., Tsukahama, Y., Watanabe, C. and Tsuge, S., J. Anal. Appl. Pyrolysis, 1993, 25, 1.

7. Fares, M. M., Yalcin, T., Hacaloglu, J., Gungor, A. and Suzer, S., Analyst, 1994, 119, 693.

8. Cameron, G. G., Bryce, W. A. J. and McWalters, I. T., Eur. Polvm. J., 1984, 20, 563 and references cited therein.

9. Ozden, B., Yalcin, T. and Suzer, S., J. Mol. Struct., 1992, 267, 135.

10. Radhakrishman, T. S. and Rao, M. R., J. Polym. Sci.: Polym. Chem. Edn, 1981, 19, 3197.
11. Chiantone, O., Cortemiglia, M. P. L. and Guaito, M., Makromol. Chem., 1989, 190, 3143.

12. Luda, M. P., Guaita, M. and Chiantore, O., Makromol. Chem., 1992, 193, 113.

13. Tamura, S. and Gillham, J. K., J. Appl. Polym. Sci., $1978,22,1867$.

14. Schneider, B., Doskocilova, D., Strakra, J. and Svoboda, M., Polymer, 1993, 34, 432.

15. Doskocilova, D., Straka, J. and Schneider, B., Polymer, 1993, 34, 437.

16. Lamb, G. D. and Lehrle, R. S., J. Anal. Appl. Pyrolysis, $1989,15,261$.

17. Hacaloglu, J., Fares, M. M. and Suzer, S., submitted to Eur. Polym. J.

18. Fares, M. M., Hacaloglu, J. and Suzer, S., Eur. Polym. J., 1994, 27, 413.

19. Madorsky, S. L., Thermal Degradation of Organic Polymers. Interscience, Newark, 1964. 